\title{
Naloxone precipitated withdrawal increases dopamine release in the dorsal striatum of opioid dependent men
}

\author{
Ehsan Shokri-Kojori $\mathbb{D}^{1 凶}$, Gene-Jack Wang ${ }^{1}$ and Nora D. Volkow (D) ${ }^{1 凶}$
}

This is a U.S. Government work and not under copyright protection in the US; foreign copyright protection may apply [year of first publication 2021

\begin{abstract}
Dopamine (DA) neurotransmission is critical in the neurobiology of reward and aversion, but its contribution to the aversive state of opioid withdrawal remains unknown in humans. To address this, we used updated voxelwise methods and retrospectively analyzed a $\left[{ }^{11} \mathrm{C}\right.$ ]raclopride-PET dataset to measure $\mathrm{D}_{2 / 3}$ receptor availability and relative cerebral blood flow (R1) in male opioid use disorder (OUD) participants $(n=10)$ during placebo and acute opioid withdrawal conditions. We found that acute withdrawal precipitated by the opioid antagonist naloxone significantly increased dorsal striatal DA release in OUD participants $\left(p_{\mathrm{FWE}}<0.05\right)$. Net changes in striatal DA were significantly correlated with a subjective index of withdrawal aversion such that greater DA increases were associated with more aversive responses $(r(8)=0.82, p<0.005)$. Withdrawal also affected brain function, as indexed by increases in relative cerebral blood flow in the insula and putamen $\left(p_{\mathrm{FWE}}<0.05\right)$. Our findings are different from preclinical studies that have primarily reported decreases in ventral striatal DA during naloxone precipitated withdrawal, whereas this effect was not significant in OUD participants $(p=0.79)$. In sum, we provide evidence for the contribution of increases in dorsal striatal DA to the aversive state of naloxone precipitated withdrawal in humans.
\end{abstract}

Translational Psychiatry (2021)11:445; https://doi.org/10.1038/s41398-021-01548-8

\section{INTRODUCTION}

The opioid epidemic is a leading health crisis in the US. Acute opioid withdrawal is an important contributor to drug-seeking behavior and relapse, and its underlying neurobiology is critical for the treatment development of opioid use disorder (OUD). Changes in opioid neurotransmission contribute to physical dependence and withdrawal symptomatology in OUD [1, 2]. Changes in the dopamine (DA) system, the main contributor to reward and aversion $[3,4]$, have been also implicated in OUD. Similar to other substance use disorders [5], OUD has been associated with decreased striatal $D_{2 / 3}$ receptor $\left(D_{2 / 3} R\right)$ availability $[6,7]$. Opioids, directly and indirectly, affect midbrain DA neurons in the ventral tegmental area (VTA) and substantia nigra pars compacta (SNc). Stimulation of mu-opioid receptor (MOR) suppresses the inhibitory effect of GABA interneurons on DA neurons in the VTA. This indirect inhibition results in increased DA release in the ventral striatum that has been associated with the rewarding effects of opioid drugs [8]. Kappa opioid receptors (KORs) also regulate DA release through their direct effect on DA neurons and are implicated in aversion including opioid withdrawal $[9,10]$. Different effects of opioid antagonists and agonists on the opioid receptors in the SNc and VTA could differentially affect DA release in the dorsal and ventral striatum [11].

Symptoms of acute opioid withdrawal primarily reflect disruptions in opioid signaling in multiple neuronal systems following repeated opioid exposure. Preclinical data indicate that acute opioid exposure stimulates MOR in the locus coeruleus (LC), suppresses norepinephrine release, and reduces adrenergic function [12]. Chronic opioid exposure increases basal LC activity, presumably, to counterbalance the repeated suppression of norepinephrine release [13]. Abrupt discontinuation of opioids or administration of opioid antagonists (such as naloxone (NAL)) markedly increases norepinephrine release and triggers systemic withdrawal symptoms [14]. Acute opioid withdrawal is stressful and stimulates the hypothalamus-pituitary-adrenal (HPA) axis, leading to increases in pituitary pro-opiomelanocortin mRNA, adrenocorticotropic hormone (ACTH), and adrenal cortisol release [15].

NAL, a non-selective opioid antagonist $[16,17]$, is used to reverse opioid overdose effects [18] and precipitates withdrawal in opioiddependent individuals. Here we aimed to study the contribution of DA to NAL precipitated withdrawal (NPW) in OUD participants. For this purpose, we employed updated voxelwise PET analysis techniques (to improve image co-registration, normalization, and reference region identification) and revisited a $\left[{ }^{11} \mathrm{C}\right]$ raclopride-PET dataset where we had assessed changes in DA release between placebo and NPW conditions in OUD men [6]. As a secondary goal, we explored the functional effects of NPW (indexed by relative cerebral blood flow, rCBF) on the pituitary (related to stress and HPA stimulation) $[15,19]$ and habenula (implicated in NAL aversion) [20]. Preclinical studies that assessed the effect of NPW on DA, have mostly focused on the ventral striatum and have reported decreases [10, 21-25] or no change in DA release [26]. In contrast, increases in DA have been reported in the dorsal striatum during NPW [27]. Thus, we hypothesized that NPW would increase

\footnotetext{
${ }^{1}$ Laboratory of Neuroimaging, National Institute on Alcohol Abuse and Alcoholism, National Institutes of Health, Bethesda, MD, USA. ${ }^{\circ}$ email: ehsan.shokrikojori@nih.gov ; nvolkow@nida.nih.gov
}

Received: 14 July 2021 Revised: 22 July 2021 Accepted: 3 August 2021

Published online: 01 September 2021 
DA in the dorsal striatum and decrease DA in the ventral striatum and that changes in striatal DA would be associated with a subjective index of withdrawal aversion.

\section{METHODS \\ Participants}

This study entailed a retrospective analysis of a $\left[{ }^{11} \mathrm{C}\right]$ raclopride-PET brain imaging dataset [6] with a total of 20 PET scans that were collected on 10 OUD participants (10 males, age $=40.8 \pm 4.3$ years) in two sessions following administration of saline (SAL) and NAL (see PET imaging and modeling). The original report [6] included 11 OUD participants with PET data collected during SAL, out of which 9 OUD participants were reported to undergo $\left[{ }^{11} \mathrm{C}\right]$ raclopride-PET imaging during NAL condition. However, after reexamination of data records, we were able to identify an additional OUD participant with $\left[{ }^{11} \mathrm{C}\right]$ raclopride-PET data for both sessions (a total of 10 OUD participants). The remaining OUD participant with $\left[{ }^{11} \mathrm{C}\right]$ raclopridePET data collected only under SAL condition was not included in this report. OUD participants were studied at Brookhaven National Laboratory and provided written informed consent that was approved by the Human Subjects Research Committee of the Brookhaven National Laboratory. OUD participants had at least one year history of continued opioid use (heroin or methadone treated) and met DSM-IV criteria for opioid dependence. OUD participants were also current smokers $(n=8)$, current marijuana users $(n=7)$, current $(n=4)$ or past $(n=3)$ cocaine users, current $(n=2)$ or past $(n=1)$ amphetamine users, and past LSD users $(n=2)$. The sample size was justified based on a recent study showing that the effect of morphine on striatal DA could be detected in 10 healthy controls [28]. Imaging data on two healthy controls were also available [6] but not included in this analysis due to the small sample size.

\section{PET imaging and modeling}

The OUD participants $(n=10)$ underwent two consecutive dynamic $\left[{ }^{11} \mathrm{C}\right]$ raclopride-PET scans (CTI-Siemens ECAT 931, 6 mm FWHM) on the same day, except for two participants who were studied on different days. The first scan with $\left[{ }^{11} \mathrm{C}\right]$ raclopride started 5-7 min following administration of intravenous (IV) SAL. After $2 \mathrm{~h}$, the second scan with $\left[{ }^{11} \mathrm{C}\right]$ raclopride was started following administration of IV NAL that was given in $0.01 \mathrm{mg} / \mathrm{kg}$ increments (every $4 \mathrm{~min}$ ) until withdrawal symptoms appeared (e.g., yawning, abdominal cramps, rhinorrhea, and tearing) [6]. OUD participants received about $0.02 \mathrm{mg} / \mathrm{kg}$ of NAL. Two participants received $0.01 \mathrm{mg} / \mathrm{kg}$ NAL and were scanned on a different day from the SAL scan. Frame-wise motion correction was applied to all scans. Both dynamic $\left[{ }^{11} \mathrm{C}\right]$ raclopridePET scans for each participant were co-registered and were normalized to MNI space (2-mm isotropic) using FSL (the FMRIB Software Library) [29] and AFNI [30] routines. To estimate $D_{2 / 3} R$ availability in OUD, dynamic $\left[{ }^{11} \mathrm{C}\right]$ raclopride-PET data were modeled in PMOD 3.9 (PMOD Technologies Ltd, Zurich, Switzerland). The simplified reference tissue model 2 (SRTM2) [31] with a cerebellar reference region was used to estimate voxelwise binding potential (BPnd) and $R 1\left(R 1=K 1 / K^{\prime} 1\right)$. $R 1$ is a proxy of $\mathrm{rCBF}$ with good agreement with $\mathrm{rCBF}$ measures obtained by $\left[{ }^{15} \mathrm{O}^{\mathrm{O}} \mathrm{H}_{2} \mathrm{O}-\mathrm{PET}[32-34]\right.$ and with high reliability for $\left[{ }^{11} \mathrm{C}\right]$ raclopride-PET [35].

\section{Voxelwise comparisons}

Voxelwise paired $t$-tests were performed to assess NAL effects on $\left[{ }^{11} \mathrm{C}\right]$ raclopride BPnd and R1 in SPM12 (Wellcome Trust Centre for Neuroimaging, London) [36]. Images were smoothed with a 5-mm full-width at halfmaximum Gaussian kernel prior to the paired $t$-test analyses. A threshold of $p \leq 0.01$ in SPM12 was used and cluster sizes were corrected for multiple comparisons in the whole brain using the random field theory to control family-wise error $\left(p_{\mathrm{FWE}}<0.05\right)$ [37].

\section{Net DA release and net $\mathrm{rCBF}$ change}

DA release was calculated by subtracting the $D_{2 / 3} R$ BPnd in the drug condition (e.g., NAL) from that in the SAL condition and dividing the result by $D_{2 / 3} R$ BPnd in the SAL condition (to normalize for regional differences in $D_{2 / 3} R$ ). Net $D A$ release was calculated by averaging DA release across the striatum. To estimate drug-induced changes in $\mathrm{rCBF}$, we subtracted $\mathrm{R} 1$ in the SAL condition from that in the drug condition and divided the result by $\mathrm{R} 1$ in the SAL condition (to normalize for regional differences in R1). Net $\mathrm{rCBF}$ change was calculated by averaging $\mathrm{rCBF}$ change across the striatum. When R1 measures are directly being compared, we use R1 in the text, otherwise, we use $\mathrm{rCBF}$ change or net $\mathrm{rCBF}$ change as defined here.

\section{Regions of interest (ROIs)}

We assessed NPW-induced changes in $\left[{ }^{11} \mathrm{C}\right]$ raclopride BPnd using a priori ROls of the dorsal (caudate and putamen combined) and ventral striatum [38]. We also performed exploratory analyses to assess the effect of NPW on R1 in the pituitary and habenula ROls. The pituitary has high MOR levels $[39,40]$, is a major source of endorphins (endogenous MOR agonist), and modulates the HPA response during NPW. Increases in pituitary R1 (measured with PET) have been observed in conditions that trigger the release of pituitary hormones [41]. For this purpose, we used T1w (available in FSL) and magnetic resonance angiography (MRA) maps [42] in the MNI space with 2-mm isotropic resolution to extract anatomical ROls for the pituitary gland and the nearby internal carotid arteries. The pituitary ROI was centered at (MNl: $x=0 \mathrm{~mm}, y=2 \mathrm{~mm}, z=-32 \mathrm{~mm}$ ) [43] and expanded to cover nearby areas with high T1w image intensity (63 voxels, $0.50 \mathrm{~mL}$ ). We used high-intensity areas in the MRA map, adjacent to the pituitary ROI, to create a bilateral internal carotid ROI (666 voxels, $5.33 \mathrm{~mL}$ ). The pituitary and carotid ROls had no spatial overlap. The habenula has notably high levels of MOR (medial habenula) [44] and also expresses KOR (lateral habenula) [45], is implicated in aversive states [46] including NPW [20], and modulates DA release [47, 48]. A bilateral habenula ROI was defined based on MNI coordinates defined in the literature [49]. An adjacent control ROI was positioned anterior to the habenula ROI. We tested the effect of NPW on R1 in both bilateral ROls and corrected for multiple comparisons for these two ROls $(n=2, p<0.025)$. Considering that the volume of the habenula was only a fraction of the spatial resolution of the PET camera, we were unable to distinguish between LHb and medial habenula (the segment implicated in NAL aversion) [20], and our habenula findings should be considered preliminary and interpreted with caution.

\section{Physiological monitoring in OUD}

Plasma levels of cortisol and prolactin, cardiovascular measures of systolic and diastolic blood pressure, and pulse rate were recorded during SAL and NAL imaging sessions according to procedures described previously [6]. To correct for multiple comparisons across physiological and subjective measures, we applied a familywise false discovery rate of 0.05 [50].

Plasma cortisol and prolactin levels were measured before, and 10, 30, and 60 min after SAL and NAL injection in 9 OUD participants but complete data was only available at 30 and $60 \mathrm{~min}$ post-injection. We averaged plasma levels at these later time points and compared the average cortisol and prolactin levels between SAL and NAL conditions.

Electrocardiographic and blood pressure recordings were obtained continuously throughout the NAL and SAL sessions (every $1 \mathrm{~min}$ for $20 \mathrm{~min}$ and then at 25,30,45, and $60 \mathrm{~min}$ ). We averaged cardiovascular data points across each session and compared the changes in cardiovascular measures between NAL and SAL sessions.

\section{Behavioral monitoring in OUD}

Subjective withdrawal experience was measured by self-reports of alertness, anxiety, annoyance, loss of control, depression, distressful thoughts, happiness, mood, restlessness, concentration, desire to use an opiate, optimism, activeness, indifference, irritability, and pain that were scored from 0 for lowest to 10 for highest. These self-reports were obtained $10 \mathrm{~min}$ pre (baseline) and 10, 30, and 60 min post-injection in each session (Supplementary Table 1). Additional measures of withdrawal symptoms (e.g., muscle twitches or shivering) were not included here due to their limited variability across participants. The subjective NAL effect was studied by comparing each of the three post-injection data points with the baseline. To estimate an index of NAL aversion, we calculated the first principle component of the (z-scored) changes across any of the subjective measures/time points that showed a significant NAL effect ( $p<0.05$, uncorrected). This component accounted for $37 \%$ of the variance of changes in these subjective measures and was used as an index of NAL aversion (see Supplementary Table 1), where higher component scores were associated with more aversion.

\section{RESULTS}

\section{Effects of NPW on striatal DA release}

A voxelwise paired $t$-test showed that NPW significantly increased DA in a cluster including the caudate and putamen of OUD participants, as measured by decreases in $\left[{ }^{11} \mathrm{C}\right]$ raclopride BPnd $\left(p_{\mathrm{FWE}}<0.05\right.$, Fig. $1 \mathrm{~A}$, Supplementary Table 2$)$. For this cluster, the mean \pm standard deviation of $\left[{ }^{11} \mathrm{C}\right]$ raclopride BPnd for $\mathrm{SAL}$ condition was $1.54 \pm 0.21$ and for NAL condition was $1.25 \pm 0.21$. 
A

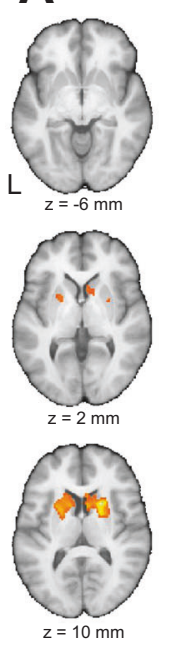

E

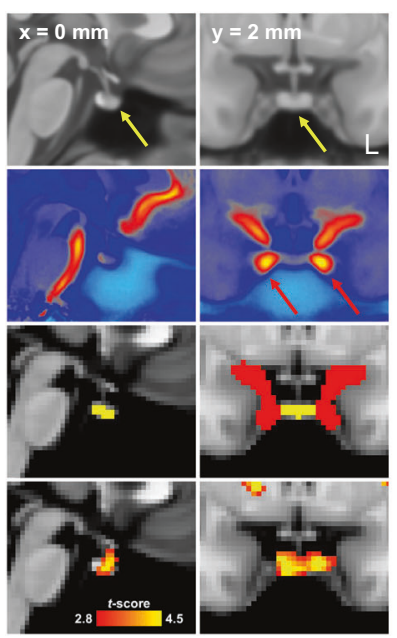

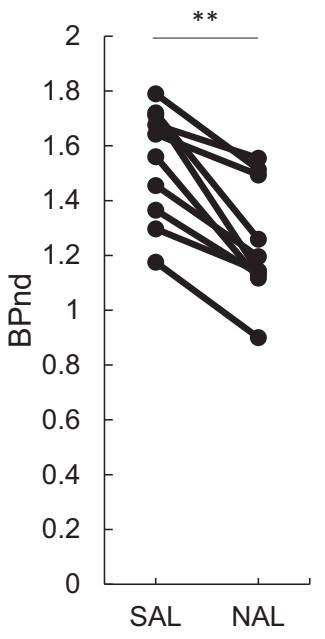

B

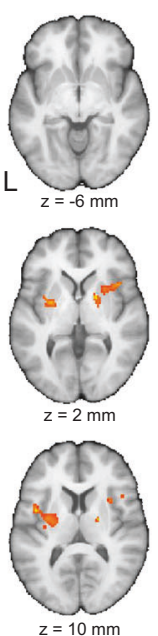

**

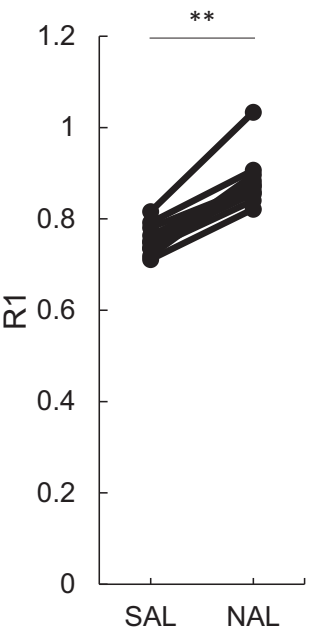

C

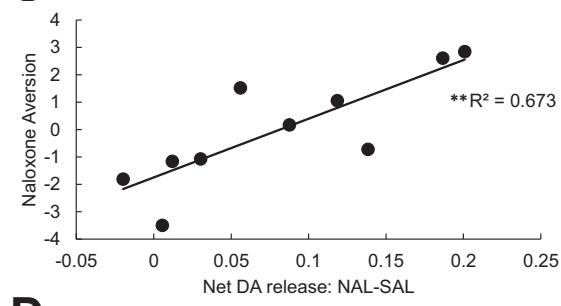

D

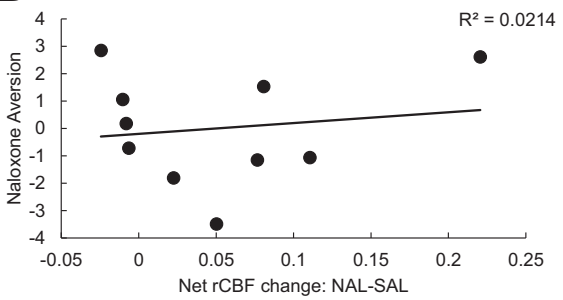

F

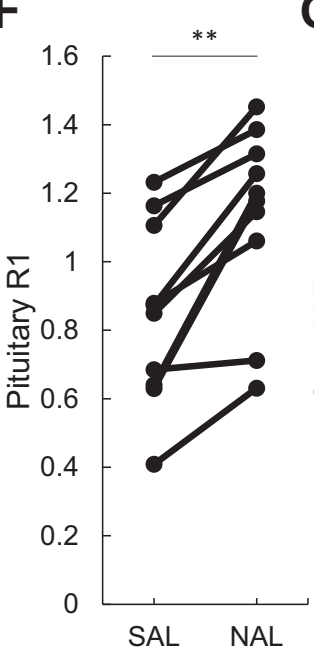

G

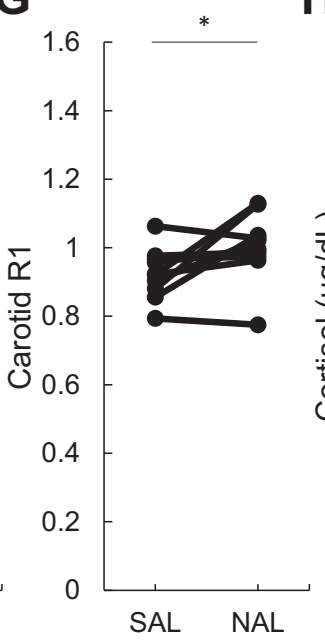

H

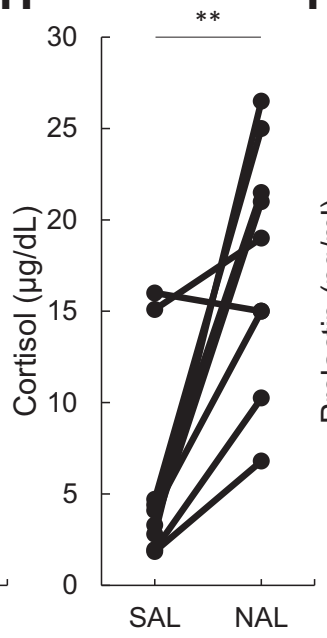

I

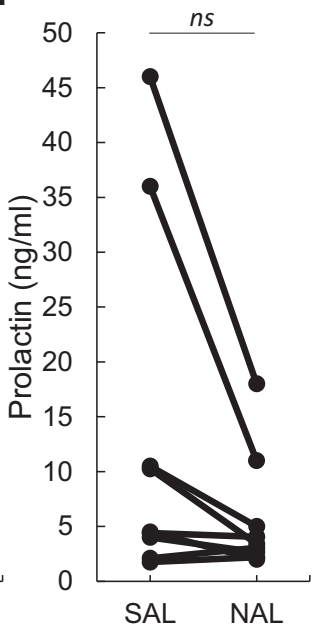

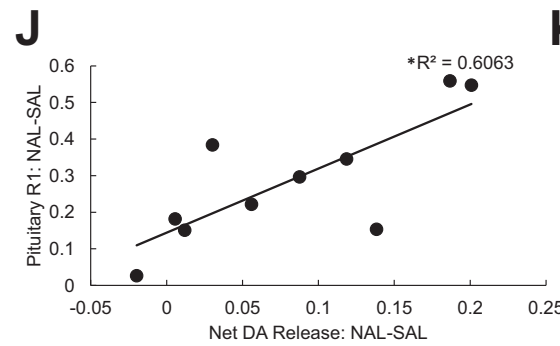

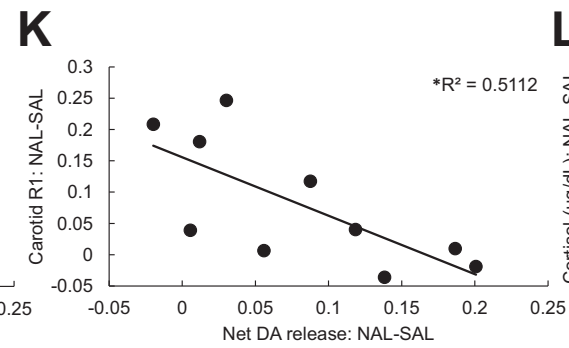

L

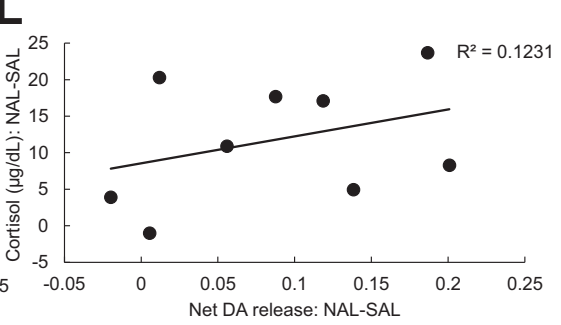

Fig. 1 Naloxone precipitated withdrawal affects dopamine release and relative cerebral blood flow in OUD men. A Voxelwise $t$-test on $\left[{ }^{11} \mathrm{C}\right]$ racloprideBPnd revealed consistent decreases in NAL compared to SAL ( $p_{\mathrm{FWE}}<0.05$ ). B Increases in R1 (a surrogate for rCBF) in the NAL compared to SAL $\left(p_{\mathrm{FWE}}<0.05\right)$. C, D Index of naloxone aversion (higher component scores indicate more aversion) was significantly associated with net increases in striatal DA-release but not with net increases in striatal rCBF (see the "Methods" section). E Left and right columns show sagittal and axial views of the human brain. First row: T1w map of human brain (0.5-mm isotropic). The yellow arrows point at the pituitary. Second row: magnetic resonance angiography map of human brain (0.5-mm isotropic) [42]. The red arrows point at the internal carotid arteries. Third row: pituitary (yellow) and internal carotid arteries (red) ROls. Fourth row: map of $t$-scores for the effect of NPW on R1 (cluster size $>200$ voxels). $\mathbf{F}$ Increases in pituitary R1 across participants with NAL compared to SAL. G Increases in carotid R1 with NAL compared to SAL. H Increases in plasma cortisol with NAL compared to SAL. I Changes in plasma prolactin with NAL compared to SAL. It was notable that the two OUD participants with hyperprolactinemia showed a large reduction in prolactin with NAL compared to SAL. J Association between net striatal DA-release and increase in pituitary R1. K Association between net striatal DA-release and increase in carotid artery R1. L Association between net striatal DA-release and increase in plasma cortisol level. ${ }^{*} p<0.05,{ }^{* *} p<0.005$.

The net increase in striatal DA release (averaged throughout the striatum, see the "Methods" section) was also significant during NPW ( $p=0.009$, Cohen's $d=1.05)$. Follow-up ROI analyses showed significant NPW-induced decreases in BPnd in the dorsal striatal
ROI (SAL BPnd: $1.93 \pm 0.27$, NAL BPnd: $1.73 \pm 0.23, p=0.005$ ) whereas no significant change in BPnd was found in the ventral striatal ROI (SAL BPnd: $1.47 \pm 0.26$, NAL BPnd: $1.46 \pm 0.28, p=0.79$ ). NPW-induced decreases in BPnd in the dorsal striatal ROI were 
significantly different from changes in BPnd in the ventral striatal ROI $(p=0.002)$.

\section{Effects of NPW on rCBF}

A voxelwise paired $t$-test showed that NPW increased R1 (indexing $\mathrm{rCBF})$ in insular and putamen regions $\left(p_{\mathrm{FWE}}<0.05\right.$, Fig. $1 \mathrm{~B}$, Supplementary Table 3). There was a trend increase in net striatal rCBF (the whole striatum, see the "Methods" section) during NPW $(p=0.06)$ though changes in the dorsal $(p=0.11)$ and ventral $(p=0.67)$ striatal ROls were not significant. Changes in net striatal DA were not significantly associated with changes in net striatal rCBF (see the "Methods" section) $(r(8)=0.005, p=0.99)$.

\section{Effects of NPW on subjective measures of withdrawal}

NPW was aversive and resulted in significant increases in selfreports of anxiety, annoyance, and restlessness and decreases in happiness and mood ( $p_{\mathrm{FDR}}<0.05$, Supplementary Table 1). A withdrawal aversion index was calculated using the first principal component of the change in subjective measures that showed a significant NAL effect (see the "Methods" section) where higher component scores were associated with more aversion. The withdrawal aversion index was significantly and positively associated with changes in net striatal DA $(r(8)=0.82, p=$ 0.0036 , Fig. $1 C)$ but not with net changes in striatal $\operatorname{rCBF}(r(8)=$ $0.14, p=0.69$, Fig. 1D).

\section{Effects of NPW on peripheral measures}

NPW elevated plasma cortisol levels and elevated cardiovascular activity (Fig. $1 \mathrm{H}, p=0.003, p_{\mathrm{FDR}}<0.05$, Supplementary Fig. 1). Changes in plasma prolactin were not significant ( $p=0.07$, Fig. 11). The positive correlation between changes in plasma cortisol and changes in net striatal DA was not significant $(r(7)=0.49, p=0.15$, Fig. 1L).

\section{ROIs analyses of $\mathbf{R} \mathbf{1}$}

NPW significantly increased R1 in the pituitary $(p=0.0006)$ and carotid ( $p=0.03$ ) ROls (Fig. 1E-G, see the "Methods" section). Net increases in striatal DA was significantly and positively associated with increases in pituitary $\mathrm{R} 1(r(8)=0.78, p=0.008$, Fig. $1 \mathrm{~J})$ but significantly and negatively with an increase in carotid R1 $(r(8)=$ $-0.71, p=0.02$, Fig. 1K). NPW also increased R1 in the habenula ROI $(p<0.025$, see Supplementary Fig. 2 and the section "Methods").

\section{DISCUSSION}

Here we document that NPW in OUD participants was associated with increased DA release in the dorsal but not ventral striatum. Increases in striatal DA release were positively associated with withdrawal aversion and with increases in pituitary R1. The findings implicate DA in the aversive experience of acute opioid withdrawal and in the concomitant activation of the HPA axis. Preclinical studies that have measured DA in the ventral striatum have shown that opioid withdrawal is associated with decreases in DA [10, 21-25, 51-54], whereas some studies have reported increases in DA particularly in the dorsal striatum $[27,55]$. We found that NPW increased DA in the dorsal striatum and the effect was significantly different from changes in the ventral striatal DA in OUD participants. However, different from the preclinical literature, we did not observe DA decreases in the ventral striatum, which could reflect differences in experimental procedures or interspecies differences.

\section{DA increases in dorsal but not ventral striatum during NPW}

The mechanisms responsible for the DA increases in the dorsal but not ventral striatum during NPW in OUD are unclear and could reflect differences in the effects of NAL on the SNc and VTA. Since NAL is a non-specific antagonist, the regional effect of NAL could be determined by the relative involvement of different opioid receptors in regulating DA neurons and DA release. For example, blockade of KOR (expressed on DA neurons and their terminals) could increase DA release $[56,57]$. This effect could be counteracted by MOR blockade which enhances the inhibition of DA neurons (decreases DA release), particularly in the VTA with higher MOR-expressing GABAergic interneurons than SNc [58]. Thus, the less inhibitory effects of MOR blockade in the SNc relative to VTA could account for relative increases in DA release in the dorsal striatum during NPW. In addition, MOR-expressing GABAergic afferents (e.g., from RMTg) interact with midbrain GABAergic interneurons and could lead to MOR antagonist-induced DA release [59]. These mechanisms of DA regulation may have been differently affected in the SNc and VTA by chronic exposure to opioids [60], which could lead to differences in DA release in the dorsal and ventral striatum during NPW. It is noteworthy that dorsal striatal DA increases during NPW were different in the location from the effect of morphine in healthy controls where DA release increased primarily in the ventral striatum [28].

\section{Aversion-related increases in striatal DA}

NPW-induced aversion was associated with net increases in striatal DA, such that OUD participants with more aversive withdrawal experiences had more DA increases. In general, DA increases, particularly in the nucleus accumbens of the ventral striatum, have been observed in response to reward and reward expectation (including drugs) [61, 62] but also aversion and stress $[63,64]$. In this respect, distinct subgroups of DA neurons with different afferent projections have been implicated in processing of reward and aversion [48]. Specifically, lateral VTA neurons encode reward and receive excitatory inputs from laterodorsal tegmentum and inhibitory inputs from the lateral habenula (LHb) via RMTg $[48,65]$. Medial VTA neurons encode aversion and receive glutamatergic inputs from the LHb [48]. Similar to VTA, different subgroups of SNc DA neurons are implicated in aversion and reward [66]. Thus, aversion-related increases in dorsal striatal DA during NPW may be consistent with excitation of dorsolateral SNc DA neurons that project to the dorsal striatum and respond to aversive stimuli $[66,67]$. The lateral habenula is a key projecting region to DA neurons and has a major role in the neurocircuitry of aversion with its indirect inhibitory control $[47,68,69]$ and direct excitatory control over the VTA and SNc [70, 71]. LHb is also modulated by opioids through KOR [45] and MOR [72]. Interestingly, though preliminary in nature, we documented a significant increase in rCBF in the habenula during NPW (Supplementary Fig. 2) that supports its involvement in acute opioid withdrawal in humans.

\section{NPW effects on striatal function}

We found a significant regional increase in $\mathrm{R} 1$ in the insula and putamen (Fig. 1B) and a trend increase in net striatal rCBF during NPW. However, the correlation between changes in net striatal DA and net striatal rCBF was not significant. Recent reports also revealed a mismatch between amplitude of striatal DA release and BOLD response (related to blood flow and a marker of brain function) [73]. Together with DA, glutamate and aspartate signaling [74] and GABAergic and cholinergic interneurons $[75,76]$, are expected to modulate striatal function during NPW. Thus, it is likely that striatal rCBF changes during NPW reflect contributions from multiple neurotransmitters [77].

\section{HPA hyperactivity during NPW}

We observed significant increases in plasma cortisol and in pituitary R1 (see the "Methods" section) that were consistent with HPA hyperactivity during NPW [78]. Opioid and DA receptors modulate HPA function [79], for example, MOR is highly expressed in the pituitary [40]. The positive association between increases in pituitary $\mathrm{R} 1$ and striatal DA release could 
reflect concomitant effects of NAL on the pituitary and DA systems [80, 81]. Previous studies have reported positive associations between striatal DA release and cortisol levels during an IV amphetamine challenge (which was generally rewarding) [82] and during an aversive psychological stressor condition [64]. This association was not significant in our study ( $r$ $(7)=0.49, p=0.15$ ) which could reflect the chronic state of stress in OUD [83] or our limited sample size.

\section{Limitations and considerations}

In a prior analysis of this dataset [6], the failure to detect striatal DA increase during NPW is likely due to limitations in imaging analysis tools. The old analysis did not rely on alignment of sessions to a common anatomical reference which could have been introduced within and between-subject variability in the hand-drawn ROls. In addition, the striatal ROls were large (spanning multiple planes) [6] which may have obscured focal effects within striatal subregions. The present study overcame these limitations by aligning participants' scans and then transferring the images to a common MNI space to identify striatal and cerebellar ROls and to assess NPW effects on striatal DA at the voxel level. Different from the old analysis, we used a simplified reference tissue model (see the section "Methods"), which does not rely on arterial input function, an approach that is potentially beneficial for eliminating another source of variability (i.e., measurement errors in arterial input function) in the kinetic modeling of PET data [84]. The main limitation of this study is the small sample size $(n=10)$. The difficulty of conducting imaging studies in OUD individuals during acute opioid withdrawal did not allow us to expand the sample size. Yet, we showed a significant and relatively large effect of NPW on striatal DA (Cohen's $d=1.05$ ) that could be clinically meaningful and merits further investigation. However, the behavioral associations with NPW-induced DA release should be interpreted with caution in our small sample. We also cannot ascertain a causal relationship between NPW-induced DA release and withdrawal aversion. Finally, because of the limited PET resolution, ROI analyses in small regions (e.g., habenula) should be considered preliminary.

\section{CONCLUSION}

Preclinical studies have shown increases or decreases in DA release or neuronal activity primarily in the ventral but also dorsal striatum in response to aversion and reward [59, 61, 63, 85, 86]. In humans, brain imaging studies have reported different BOLD activation in the dorsal and ventral striatum with aversive and rewarding stimuli $[63,87-89]$. Other than a prior study showing that psychological stress increased striatal DA release in the human ventral striatum [64], our findings are the first to document in humans that a druginduced aversive and stressful state was associated with DA increases in the dorsal striatum. We also showed that the striatal DA increases were associated with the severity of opioid withdrawal experience. These observations support the contribution of DA to opioid-related aversion and could be relevant for the development of treatments for OUD $[90,91]$.

\section{DATA AVAILABILITY}

Most data are included in the manuscript and supplementary information and are availabe upon request.

\section{REFERENCES}

1. Cox B.M. Opioid Receptor-G Protein Interactions: Acute and Chronic Effects of Opioids. In: Herz A., Akil H., Simon E.J. (eds) Opioids. Handbook of Experimental Pharmacology, vol 104 / 1. Springer: Berlin, Heidelberg, 1993, pp 145-188, https://doi.org/10.1007/978-3-642-77460-7_8.

2. Merrer JL, Becker JAJ, Befort K, Kieffer BL. Reward processing by the opioid system in the brain. Physiol Rev. 2009;89:1379-412.
3. Pignatelli $M$, Bonci A. Role of dopamine neurons in reward and aversion: a synaptic plasticity perspective. Neuron. 2015;86:1145-57.

4. Volkow ND, Wise RA, Baler R. The dopamine motive system: implications for drug and food addiction. Nat Rev Neurosci. 2017;18:741-52.

5. Volkow N, Fowler J, Wang G, Baler R, Telang F. Imaging dopamine's role in drug abuse and addiction. Neuropharmacology. 2009;56:3-8.

6. Wang G-J, Volkow ND, Fowler JS, Logan J, Abumrad NN, Hitzemann RJ, et al. Dopamine D2 receptor availability in opiate-dependent subjects before and after naloxone-precipitated withdrawal. Neuropsychopharmacology. 1997;16:174-82.

7. Martinez D, Saccone PA, Liu F, Slifstein M, Orlowska D, Grassetti A, et al. Deficits in dopamine D2 receptors and presynaptic dopamine in heroin dependence: commonalities and differences with other types of addiction. Biol Psychiatry. 2012;71:192-8

8. Devine DP, Leone P, Pocock D, Wise R. Differential involvement of ventral tegmental $\mathrm{mu}$, delta and kappa opioid receptors in modulation of basal mesolimbic dopamine release: in vivo microdialysis studies. J Pharmacol Exp Ther. 1993;266:1236-46.

9. Chefer VI, Bäckman CM, Gigante ED, Shippenberg TS. Kappa opioid receptors on dopaminergic neurons are necessary for Kappa-mediated place aversion. Neuropsychopharmacology. 2013;38:2623-31.

10. Spanagel R, Almeida OF, Bartl C, Shippenberg TS. Endogenous K-opioid systems in opiate withdrawal: role in aversion and accompanying changes in mesolimbic dopamine release. Psychopharmacology. 1994;115:121-7.

11. Nazzaro J, Seeger T, Gardner E. Morphine differentially affects ventral tegmental and substantia nigra brain reward thresholds. Pharmacol Biochem Behav. 1981;14:325-31.

12. Samuels ER, Szabadi E. Functional neuroanatomy of the noradrenergic locus coeruleus: its roles in the regulation of arousal and autonomic function part I: principles of functional organisation. Curr Neuropharmacol. 2008;6:235-53.

13. Kosten TR, George TP. The neurobiology of opioid dependence: implications for treatment. Sci Pract Perspect. 2002;1:13-20.

14. Rasmussen K. Afferent effects on locus coeruleus in opiate withdrawal. Prog Brain Res. 1991;88:207-16.

15. Zhou Y, Leri F, Ho A, Kreek MJ. Suppression of hypothalamic-pituitary-adrenal axis by acute heroin challenge in rats during acute and chronic withdrawal from chronic heroin administration. Neurochem Res. 2013;38:1850-60.

16. Wang D, Sun X, Sadee W. Different effects of opioid antagonists on $\mu-, \delta$-, and $\mathrm{K}^{-}$ opioid receptors with and without agonist pretreatment. J Pharmacol Exp Ther. 2007;321:544-52.

17. Raynor K, Kong H, Chen Y, Yasuda K, Yu L, Bell Gl, et al. Pharmacological characterization of the cloned kappa-, delta-, and mu-opioid receptors. Mol Pharmacol. 1994;45:330-4.

18. Shaw LV, Moe J, Purssell R, Buxton JA, Godwin J, Doyle-Waters MM, et al. Naloxone interventions in opioid overdoses: a systematic review protocol. Syst Rev. 2019;8:1-9.

19. Caron MG, Beaulieu M, Raymond V, Gagné B, Drouin J, Lefkowitz RJ, et al. Dopaminergic receptors in the anterior pituitary gland. Correlation of $[3 \mathrm{H}]$ dihydroergocryptine binding with the dopaminergic control of prolactin release. J Biol Chem. 1978;253:2244-53.

20. Boulos L, Ben Hamida S, Bailly J, Maitra M, Ehrlich AT, Gavériaux-Ruff C, et al. Mu opioid receptors in the medial habenula contribute to naloxone aversion. Neuropsychopharmacology. 2020;45:247-55.

21. Acquas E, Carboni E, Di Chiara G. Profound depression of mesolimbic dopamine release after morphine withdrawal in dependent rats. Eur J Pharm. 1991;193:133-4.

22. Pothos E, Rada P, Mark GP, Hoebel BG. Dopamine microdialysis in the nucleus accumbens during acute and chronic morphine, naloxone-precipitated withdrawal and clonidine treatment. Brain Res. 1991;566:348-50.

23. Rossetti ZL, Hmaidan Y, Gessa GL. Marked inhibition of mesolimbic dopamine release: a common feature of ethanol, morphine, cocaine and amphetamine abstinence in rats. Eur J Pharm. 1992;221:227-34.

24. Zhou Q, Nyberg F. Injection of substance $P(S P)$ N-terminal fragment SP(1-7) into the ventral tegmental area modulates the levels of nucleus accumbens dopamine and dihydroxyphenylacetic acid in male rats during morphine withdrawal. Neurosci Lett. 2002;320:117-20.

25. Stella L, De Novellis V, Vitelli MR, Capuano A, Mazzeo F, Berrino L, et al. Interactive role of adenosine and dopamine in the opiate withdrawal syndrome. NaunynSchmiedeberg's Arch Pharmacol. 2003;368:113-8.

26. Silverstone $\mathrm{PH}$, Done $\mathrm{C}$, Sharp $\mathrm{T}$. In vivo monoamine release during naloxoneprecipitated morphine withdrawal. Neuroreport. 1993;4:1043-5.

27. Iwamoto E, Ho I, Way EL. Elevation of brain dopamine during naloxoneprecipitated withdrawal in morphine-dependent mice and rats. J Pharmacol Exp Ther. 1973;187:558-67.

28. Spagnolo PA, Kimes A, Schwandt ML, Shokri-Kojori E, Thada S, Phillips KA. et al. Striatal dopamine release in response to morphine: a [11C]-raclopride positron emission tomography study in healthy men. Biol Psychiatry. 2019;86:356-364. 
29. Jenkinson M, Beckmann CF, Behrens TEJ, Woolrich MW, Smith SM. FSL. NeuroImage. 2012;62:782-90.

30. Cox RW. AFNI: software for analysis and visualization of functional magnetic resonance neuroimages. Comput Biomed Res. 1996;29:162-73.

31. $\mathrm{Wu} Y$, Carson RE. Noise reduction in the simplified reference tissue model for neuroreceptor functional imaging. J Cereb Blood Flow Metab. 2002;22:1440-52.

32. Meyer PT, Hellwig S, Amtage F, Rottenburger C, Sahm U, Reuland P, et al. Dualbiomarker imaging of regional cerebral amyloid load and neuronal activity in dementia with PET and 11C-labeled Pittsburgh compound B. J Nucl Med. 2011;52:393-400.

33. Chen YJ, Rosario BL, Mowrey W, Laymon CM, Lu X, Lopez OL, et al. Relative 11C$\mathrm{PiB}$ delivery as a proxy of relative $\mathrm{CBF}$ : quantitative evaluation using singlesession 15O-water and 11C-PiB PET. J Nucl Med. 2015;56:1199-205.

34. Bilgel M, Beason-Held L, An Y, Zhou Y, Wong DF, Resnick SM. Longitudinal evaluation of surrogates of regional cerebral blood flow computed from dynamic amyloid PET imaging. J Cereb Blood Flow Metab. 2020;40:288-97.

35. Stokes PR, Egerton A, Watson B, Reid A, Breen G, Lingford-Hughes A, et al. Significant decreases in frontal and temporal [11C]-raclopride binding after THC challenge. Neurolmage. 2010;52:1521-7.

36. Friston KJ, Holmes AP, Poline JB, Grasby PJ, Williams SC, Frackowiak RS, et al. Analysis of fMRI time-series revisited. Neurolmage. 1995;2:45-53.

37. Poline J-B, Worsley KJ, Evans AC, Friston KJ. Combining spatial extent and peak intensity to test for activations in functional imaging. Neuroimage. 1997;5:83-96.

38. Tziortzi AC, Haber SN, Searle GE, Tsoumpas C, Long CJ, Shotbolt P, et al. Connectivitybased functional analysis of dopamine release in the striatum using diffusionweighted MRI and positron emission tomography. Cereb Cortex. 2014;24:1165-77.

39. Smith YR, Zubieta JK, del Carmen MG, Dannals RF, Ravert HT, Zacur HA, et al. Brain opioid receptor measurements by positron emission tomography in normal cycling women: relationship to luteinizing hormone pulsatility and gonadal steroid hormones 1. J Clin Endocrinol Metab. 1998;83:4498-505.

40. Cumming P, Marton J, Lilius TO, Olberg DE, Rominger A. A survey of molecular imaging of opioid receptors. Molecules. 2019;24:4190.

41. Huynh HK, Willemsen ATM, Holstege G. Female orgasm but not male ejaculation activates the pituitary. A PET-neuro-imaging study. Neurolmage. 2013;76:178-82.

42. Mouches P, Forkert ND. A statistical atlas of cerebral arteries generated using multi-center MRA datasets from healthy subjects. Sci Data. 2019;6:29.

43. Rucker P, Ikuta T. Pituitary gland functional connectivity and BMI. Front Neurosci. 2019;13:120

44. Gardon O, Faget L, Chu Sin Chung P, Matifas A, Massotte D, Kieffer BL. Expression of mu opioid receptor in dorsal diencephalic conduction system: new insights for the medial habenula. Neuroscience. 2014;277:595-609.

45. Chen C, Willhouse AH, Huang P, Ko N, Wang $Y$, Xu B, et al. Characterization of a knock-in mouse line expressing a fusion protein of $\mathrm{K}$ opioid receptor conjugated with tdTomato: 3-dimensional brain imaging via CLARITY. eNeuro 2020; 7: ENEURO.0028-0020.2020.

46. Lazaridis I, Tzortzi $O$, Weglage $M$, Märtin $A$, Xuan $Y$, Parent $M$, et al. A hypothalamus-habenula circuit controls aversion. Mol Psychiatry. 2019;24:1351-68.

47. Christoph GR, Leonzio RJ, Wilcox KS. Stimulation of the lateral habenula inhibits dopamine-containing neurons in the substantia nigra and ventral tegmental area of the rat. J Neurosci. 1986;6:613-9.

48. Lammel S, Lim BK, Ran C, Huang KW, Betley MJ, Tye KM, et al. Input-specific control of reward and aversion in the ventral tegmental area. Nature. 2012;491:212-7.

49. Lawson RP, Drevets WC, Roiser JP. Defining the habenula in human neuroimaging studies. Neuroimage. 2013;64:722-7.

50. Benjamini $Y$, Hochberg $Y$. Controlling the false discovery rate: a practical and powerful approach to multiple testing. J R Stat Soc: Ser B. 1995;57:289-300.

51. Tjon GH, De Vries TJ, Ronken E, Hogenboom F, Wardeh G, Mulder AH, et al. Repeated and chronic morphine administration causes differential long-lasting changes in dopaminergic neurotransmission in rat striatum without changing its $\delta$ - and K-opioid receptor regulation. Eur J Pharmacol. 1994;252:205-12.

52. Grasing K, Ghosh S. Selegiline prevents long-term changes in dopamine efflux and stress immobility during the second and third weeks of abstinence following opiate withdrawal. Neuropharmacology. 1998;37:1007-17.

53. Erhardt A, Sillaber I, Welt T, Müller MB, Singewald N, Keck ME. Repetitive transcranial magnetic stimulation increases the release of dopamine in the nucleus accumbens shell of morphine-sensitized rats during abstinence. Neuropsychopharmacology. 2004;29:2074-80.

54. Bland ST, Hutchinson MR, Maier SF, Watkins LR, Johnson KW. The glial activation inhibitor AV411 reduces morphine-induced nucleus accumbens dopamine release. Brain Behav Immun. 2009;23:492-7.

55. Maruyama $Y$, Takemori AE. The role of dopamine and norepinephrine in the naloxone-induced abstinence of morphine-dependent mice. J Pharm Exp Ther. 1973;185:602-8.
56. Spanagel R, Herz A, Shippenberg TS. Opposing tonically active endogenous opioid systems modulate the mesolimbic dopaminergic pathway. Proc Natl Acad Sci USA. 1992;89:2046-50.

57. Van't Veer A, Bechtholt AJ, Onvani S, Potter D, Wang Y, Liu-Chen LY, et al. Ablation of Kappa-opioid receptors from brain dopamine neurons has anxiolyticlike effects and enhances cocaine-induced plasticity. Neuropsychopharmacology. 2013;38:1585-97.

58. Margolis EB, Toy $B$, Himmels $P$, Morales $M$, Fields $H L$. Identification of rat ventral tegmental area GABAergic neurons. PLoS ONE. 2012;7:e42365.

59. Devine DP, Leone $P$, Wise RA. Mesolimbic dopamine neurotransmission is increased by administration of $\mu$-opioid receptor antagonists. Eur J Pharmacol. 1993;243:55-64.

60. Williams JT, Christie MJ, Manzoni O. Cellular and synaptic adaptations mediating opioid dependence. Physiol Rev. 2001;81:299-343.

61. Fields HL, Margolis EB. Understanding opioid reward. Trends Neurosci. 2015;38:217-25.

62. Berridge KC. The debate over dopamine's role in reward: the case for incentive salience. Psychopharmacology. 2007;191:391-431.

63. Salamone JD, Correa M. The mysterious motivational functions of mesolimbic dopamine. Neuron. 2012;76:470-85.

64. Pruessner JC, Champagne F, Meaney MJ, Dagher A. Dopamine release in response to a psychological stress in humans and its relationship to early life maternal care: a positron emission tomography study using [11C] raclopride. J Neurosci. 2004;24:2825-31.

65. Steidl S, Wang H, Ordonez M, Zhang S, Morales M. Optogenetic excitation in the ventral tegmental area of glutamatergic or cholinergic inputs from the laterodorsal tegmental area drives reward. Eur J Neurosci. 2017;45:559-71.

66. Matsumoto M, Hikosaka O. Two types of dopamine neuron distinctly convey positive and negative motivational signals. Nature. 2009;459:837-41.

67. Pauli WM, Larsen T, Collette S, Tyszka JM, Seymour B, O'Doherty JP. Distinct contributions of ventromedial and dorsolateral subregions of the human substantia nigra to appetitive and aversive learning. J Neurosci. 2015;35:14220-33.

68. Brown PL, Palacorolla H, Brady D, Riegger K, Elmer GI, Shepard PD. Habenulainduced inhibition of midbrain dopamine neurons is diminished by lesions of the rostromedial tegmental nucleus. J Neurosci. 2017;37:217-25.

69. Matsumoto $M$, Hikosaka O. Lateral habenula as a source of negative reward signals in dopamine neurons. Nature. 2007;447:1111-5.

70. Brown PL, Shepard PD. Functional evidence for a direct excitatory projection from the lateral habenula to the ventral tegmental area in the rat. J Neurophysiol. 2016;116:1161-74.

71. Namboodiri VMK, Rodriguez-Romaguera J, Stuber GD. The habenula. Curr Biol. 2016;26:R873-R877.

72. Margolis EB, Fields HL. Mu opioid receptor actions in the lateral habenula. PLoS ONE. 2016;11:e0159097.

73. Li N, Jasanoff A. Local and global consequences of reward-evoked striatal dopamine release. Nature. 2020;580:239-44.

74. Sepulveda MJ, Hernandez L, Rada P, Tucci S, Contreras E. Effect of precipitated withdrawal on extracellular glutamate and aspartate in the nucleus accumbens of chronically morphine-treated rats: an in vivo microdialysis study. Pharmacol Biochem Behav. 1998:60:255-62.

75. Chieng B, Williams JT. Increased opioid inhibition of GABA release in nucleus accumbens during morphine withdrawal. J Neurosci. 1998;18:7033-9.

76. Neugebauer NM, Einstein EB, Lopez MB, McClure-Begley TD, Mineur YS, Picciotto MR. Morphine dependence and withdrawal induced changes in cholinergic signaling. Pharmacol Biochem Behav. 2013;109:77-83.

77. Lorenz RC, Gleich T, Buchert R, Schlagenhauf F, Kühn S, Gallinat J. Interactions between glutamate, dopamine, and the neuronal signature of response inhibition in the human striatum. Hum Brain Mapp. 2015;36:4031-40.

78. Zhang G-F, Ren YP, Sheng LX, Chi Y, Du WJ, Guo S, et al. Dysfunction of the hypothalamic-pituitary-adrenal axis in opioid dependent subjects: effects of acute and protracted abstinence. Am J Drug Alcohol Abus. 2008;34:760-8.

79. Adamson W, Windh R, Blackford S, Kuhn C. Ontogeny of $\mu$-and k-opiate receptor control of the hypothalamo-pituitary-adrenal axis in rats. Endocrinology. 1991;129:959-64.

80. Wand GS, Weerts EM, Kuwabara H, Frost JJ, Xu X, McCaul ME. Naloxone-induced cortisol predicts mu opioid receptor binding potential in specific brain regions of healthy subjects. Psychoneuroendocrinology. 2011;36:1453-9.

81. Wand GS, Weerts EM, Kuwabara H, Wong DF, Xu X, McCaul ME. The relationship between naloxone-induced cortisol and delta opioid receptor availability in mesolimbic structures is disrupted in alcohol-dependent subjects. Addict Biol. 2013;18:181-92.

82. Oswald LM, Wong DF, McCaul M, Zhou Y, Kuwabara H, Choi L, et al. Relationships among ventral striatal dopamine release, cortisol secretion, and subjective responses to amphetamine. Neuropsychopharmacology. 2005;30:821-32. 
83. Yang J, Li J, Xu G, Zhang J, Chen Z, Lu Z, et al. Elevated hair cortisol levels among heroin addicts on current methadone maintenance compared to controls. PLoS ONE. 2016;11:e0150729.

84. Lammertsma AA, Bench CJ, Hume SP, Osman S, Gunn K, Brooks DJ, et al. Comparison of methods for analysis of clinical [11C] raclopride studies. J Cereb Blood Flow Metab. 1996;16:42-52.

85. Shippenburg T, Bals-Kubik R. Involvement of the mesolimbic dopamine system in mediating the aversive effects of opioid antagonists in the rat. Behav Pharmacol. 1995;6:99-106.

86. Steidl S, Wasserman DI, Blaha CD, Yeomans JS. Opioid-induced rewards, locomotion, and dopamine activation: a proposed model for control by mesopontine and rostromedial tegmental neurons. Neurosci Biobehav Rev. 2017;83:72-82.

87. Delgado MR, Jou RL, Phelps EA. Neural systems underlying aversive conditioning in humans with primary and secondary reinforcers. Front Neurosci. 2011;5:71-71.

88. Baliki MN, Geha PY, Fields HL, Apkarian AV. Predicting value of pain and analgesia: nucleus accumbens response to noxious stimuli changes in the presence of chronic pain. Neuron. 2010;66:149-60.

89. Delgado MR, Nystrom LE, Fissell C, Noll DC, Fiez JA. Tracking the Hemodynamic Responses To Reward And Punishment In The Striatum. J Neurophysiol. 2000;84:3072-7.

90. Mahoney JJ III, Haut MW, Hodder SL, Zheng W, Lander LR, Berry JH, et al. Deep brain stimulation of the nucleus accumbens/ventral capsule for severe and intractable opioid and benzodiazepine use disorder. Exp Clin Psychopharmacol. 2021;29:210-5.

91. Karkalas J, Lal H. A comparison of haloperidol with methadone in blocking heroin-withdrawal symptoms. Int Pharmacopsychiatry. 1973;8:248-51.

\section{ACKNOWLEDGEMENTS}

We thank Christopher Wong for assistance with behavioral and imaging data. We thank memebers of Laboratory of Neuroimaging at the NIAAA for their support.

\section{AUTHOR CONTRIBUTIONS}

ES-K and NDV designed the study, interpreted the data, and wrote the manuscript ES-K performed the analyses. NDV and G-JW collected the data. All authors commented on the manuscript.

\section{FUNDING}

This work was supported by NIAAA intramural research program (Grant Y1AA3009). Open Access funding provided by the National Institutes of Health (NIH).

\section{COMPETING INTERESTS}

The authors declare no competing interests.

\section{ADDITIONAL INFORMATION}

Supplementary information The online version contains supplementary material available at https://doi.org/10.1038/s41398-021-01548-8.

Correspondence and requests for materials should be addressed to E.S-K. or N.D.V.

Reprints and permission information is available at http://www.nature.com/ reprints

Publisher's note Springer Nature remains neutral with regard to jurisdictional claims in published maps and institutional affiliations.

(i) Open Access This article is licensed under a Creative Commons Attribution 4.0 International License, which permits use, sharing, adaptation, distribution and reproduction in any medium or format, as long as you give appropriate credit to the original author(s) and the source, provide a link to the Creative Commons license, and indicate if changes were made. The images or other third party material in this article are included in the article's Creative Commons license, unless indicated otherwise in a credit line to the material. If material is not included in the article's Creative Commons license and your intended use is not permitted by statutory regulation or exceeds the permitted use, you will need to obtain permission directly from the copyright holder. To view a copy of this license, visit http://creativecommons. org/licenses/by/4.0/.

This is a U.S. Government work and not under copyright protection in the US; foreign copyright protection may apply [year of first publication 2021 